\title{
(C) OPEN ACCESS \\ Fluoride exposure and indicators of thyroid functioning in the Canadian population: implications for community water fluoridation
}

\author{
Amanda M Barberio, ${ }^{1,2}$ F Shaun Hosein, ${ }^{3}$ Carlos Quiñonez, ${ }^{4}$ Lindsay McLaren ${ }^{2}$
}

\begin{abstract}
${ }^{1}$ Department of Cancer Epidemiology and Prevention Research, Alberta Health Services, Calgary, Alberta, Canada

${ }^{2}$ Department of Community Health Sciences and O'Brien Institute for Public Health, University of Calgary, Calgary, Alberta, Canada ${ }^{3}$ Faculty of Medicine, University of Queensland, Herston, Queensland, Australia ${ }^{4}$ Dental Public Health, Faculty of Dentistry, University of Toronto, Toronto, Ontario, Canada
\end{abstract}

\section{Correspondence to} Dr Lindsay McLaren, Department of Community Health Sciences and $\mathrm{O}^{\prime}$ Brien Institute for Public Health, University of Calgary TRW3, 3280 Hospital Dr. NW Calgary, Alberta, Canada, T2N 4Z6(403) 210-9424; Imclaren@ ucalgary.ca

Received 27 February 2017 Revised 29 June 2017 Accepted 8 July 2017 Published Online First 24 August 2017

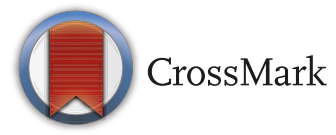

To cite: Barberio AM, Hosein FS, Quiñonez C, et al. $J$ Epidemiol Community Health 2017;71:1019-1025.

\begin{abstract}
Background There are concerns that altered thyroid functioning could be the result of ingesting too much fluoride. Community water fluoridation (CWF) is an important source of fluoride exposure. Our objectives were to examine the association between fluoride exposure and (1) diagnosis of a thyroid condition and (2) indicators of thyroid functioning among a national population-based sample of Canadians.
\end{abstract}

Methods We analysed data from Cycles 2 and 3 of the Canadian Health Measures Survey (CHMS). Logistic regression was used to assess associations between fluoride from urine and tap water samples and the diagnosis of a thyroid condition. Multinomial logistic regression was used to examine the relationship between fluoride exposure and thyroid-stimulating hormone (TSH) level (low/normal/high). Other available variables permitted additional exploratory analyses among the subset of participants for whom we could discern some fluoride exposure from drinking water and/ or dental products.

Results There was no evidence of a relationship between fluoride exposure (from urine and tap water) and the diagnosis of a thyroid condition. There was no statistically significant association between fluoride exposure and abnormal (low or high) TSH levels relative to normal TSH levels. Rerunning the models with the sample constrained to the subset of participants for whom we could discern some source(s) of fluoride exposure from drinking water and/or dental products revealed no significant associations.

Conclusion These analyses suggest that, at the population level, fluoride exposure is not associated with impaired thyroid functioning in a time and place where multiple sources of fluoride exposure, including CWF, exist.

\section{BACKGROUND}

The objective of this study was to examine the association between fluoride exposure and thyroid functioning among a national population-based sample of Canadians. As described below, fluoride is one of the several factors that could be relevant to thyroid-related problems; however, existing human studies have yielded mixed findings.

Thyroid underactivity (hypothyroidism) is most commonly caused by an autoimmune disease known as Hashimoto's thyroiditis but can also occur due to the use of certain medications (eg, lithium) and both increased and decreased iodine intake. Thyroid overactivity (hyperthyroidism) is most commonly caused by an autoimmune disease known as Graves' disease but can also result from inflammation of the thyroid, excessive iodine intake and thyroid adenomas. ${ }^{1}$ Risk factors for thyroid diseases include, but are not limited to sex (female), age (over 50), family history of thyroid disease, smoking cigarettes and radiation exposure to the head or neck. ${ }^{2}$ Additionally, individuals with one autoimmune condition are more susceptible to developing other autoimmune conditions. For example, individuals with celiac disease have been found to have significantly higher risk of developing autoimmune thyroid diseases. ${ }^{3}$

Animal studies have indicated that high concentrations of fluoride impair thyroid function. ${ }^{4}$ Decreases in triiodothyronine (T3) and thyroxine (T4), thyroid peroxidase and 3G-leucine were observed in laboratory animals administered fluoride at doses of $3-6 \mathrm{mg} / \mathrm{kg} /$ day. When iodine intake was low, larger effects on thyroid function were noted. Several mechanisms of action, such as lowered production of thyroid hormone, thyroid hormone transportation abnormalities in the blood and interference related to the conversion of T4-T3 in the peripheral tissues by deiodinases, have been proposed to explain these effects, but the mechanistic details have yet to be elucidated. ${ }^{4}$

Human studies investigating the relationship between fluoride exposure and thyroid functioning have mixed findings. Three studies conducted in India ${ }^{5-7}$ and one in China ${ }^{8}$ found evidence of at least one hormone derangement among those deemed as having 'high' fluoride exposure (defined in various ways), but the studies differed in terms of the hormone derangement patterns observed. For example, Michael et al (1996) $)^{5}$ found no difference in the levels of thyroid-stimulating hormone (TSH) between those with low and high fluoride exposure (fluoride exposure was not clearly defined), whereas Lin et al (1991) ${ }^{8}$ found that individuals residing in high fluoride areas (defined as areas with an average fluoride concentration of 0.88 parts per million (ppm) in drinking water) had significantly higher TSH levels than those residing in low fluoride areas (average fluoride concentration of 0.34 $\mathrm{ppm}$ in drinking water $)(\mathrm{p}<0.01)$. Conversely, a

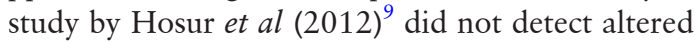
levels of thyroid hormones (free T3, free T4 and TSH) in 65 individuals living in India with dental fluorosis (used as a proxy for high fluoride exposure), with the exception of one individual whose serum levels of TSH were elevated. The results 
of these small-scale human studies should be interpreted with caution in light of limited details regarding the study sample, unclear descriptions of fluoride exposure classification and lack of adjustment for other important covariates (eg, iodine status). ${ }^{4}$ Importantly, none of these studies were conducted in the context of community water fluoridation (CWF), making their relevance to CWF and the Canadian population unclear.

CWF is a public health intervention that functions to prevent tooth decay by adding a controlled quantity of fluoride to public drinking water supplies and represents an important source of fluoride exposure in fluoridated regions. ${ }^{10}$ A Fluoride Expert Panel commissioned by Health Canada determined the optimal concentration of fluoride in public drinking water supplies to be $0.7 \mathrm{mg} / \mathrm{L}$, as available evidence suggests that this concentration balances the protective dental benefits of fluoride with potential adverse health effects (eg, dental fluorosis). ${ }^{11}$ However, concerns remain that the concentration of fluoride in drinking water supplies is still too high and could compromise thyroid functioning, ${ }^{12}$ especially when multiple sources of fluoride exist (eg, fluoride-containing dental products).

The results of a recent cross-sectional study by Peckham, Lowery and Spencer $(2015)^{13}$ appear to add legitimacy to concerns regarding fluoride exposure from CWF and impaired thyroid functioning. Data on diagnosed hypothyroidism during 2012-2013 were obtained from all primary care physicians' offices in England and mapped to water supply zones and corresponding fluoride levels. Binary logistic regression was used to examine the association between high general practitioner (GP) practice level hypothyroidism prevalence (top tertile, 3.58\%$8.48 \%$ ) and fluoride concentrations in drinking water (low $(\leq 0.3 \mathrm{ppm})$, medium $(>0.3$ to $\geq 0.7 \mathrm{ppm})$ and high $(>0.7$ $\mathrm{ppm})$ ), controlling for aggregate (GP practice level) gender, age and deprivation scores. Areas with high fluoride concentrations were 1.6 times more likely to have high GP practice level hypothyroidism prevalence than areas with low fluoride concentrations. $^{13}$

Since Peckham et al $(2015)^{13}$ was the first population-level study to examine the relationship between CWF and thyroid problems (in particular, hypothyroidism), additional research is required to determine if these findings are consistent across different contexts, and when individual-level biomarkers of fluoride exposure are used.

The present study utilised high-quality Canadian survey data from a national population-based sample that includes individual-level estimates of fluoride exposure from urine and tap water samples, as well as measures of thyroid functioning. Our objectives were to examine the association between fluoride exposure and (1) the diagnosis of a thyroid condition and (2) indicators of thyroid functioning, specifically TSH and free T4 levels, among a population-based sample of Canadians.

\section{METHODS}

\section{Data source and target population}

The data source is Cycles 2 (2009-2011) and 3 (2012-2013) of Statistics Canada's Canadian Health Measures Survey (CHMS); specifically, the environmental urine subsample $(n=2563)$ for Cycle 2 and the urine fluoride subsample $(n=2671)$ for Cycle 3. Full survey details are available at www.statcan.gc.ca. Briefly, the CHMS is a nationally representative, cross-sectional survey that collects health information from individuals through an in-home interview followed by a clinical exam conducted in a mobile clinic. The target population is all Canadian residents age 3-79 years living in the ten provinces, excluding those who live in the three territories (Cycle 3 only), those who live on reserves and other Aboriginal settlements in the provinces, institutionalised residents, full-time members of the Canadian Forces and residents of certain remote regions. Cumulatively, these excluded groups represent about $4 \%$ of the target population. ${ }^{14}{ }^{15}$ Nationally representative samples were drawn using a stratified, multistage sampling strategy. The overall response rates were 55.5\% (Cycle 2) and 51.7\% (Cycle 3). Response rates were $54.4 \%$ for the environmental urine subsample (Cycle 2) and $55.6 \%$ for the urine fluoride subsample (Cycle 3). ${ }^{14} 15$

\section{Variables of interest}

Estimates of urinary fluoride from spot urine were available for a subsample of respondents. The fluoride content of urine samples was analysed using an Orion $\mathrm{pH}$ metre with fluoride ion selective electrode with a limit of detection of $20 \mu \mathrm{g} / \mathrm{L}$ (Cycle 2) and $10 \mu \mathrm{g} / \mathrm{L}$ (Cycle 3). ${ }^{1617}$ Analysis was performed under standardised operating procedures at the Human Toxicology Laboratory of the Institut National de Santé Publique du Québec (accredited under ISO 17025). Urinary fluoride has been shown to be sensitive to variations in fluoride exposure, including $\mathrm{CWF},{ }^{18}$ and has been classified as a contemporary marker of fluoride exposure as opposed to recent (eg, hair and nails) or historic (eg, bone and teeth) markers. ${ }^{19}$

In Cycle 3 only, estimates of the fluoride concentration of tap water samples collected from randomly selected households were available. The subsample of households selected for tap water sample collection corresponded to the person-level urine fluoride subsample. Analysis of the fluoride concentration of tap water was performed using a basic anion exchange chromatography procedure, with a limit of detection of $0.006 \mathrm{mg} / \mathrm{L}$.

Thyroid functioning was measured in three ways: (1) self-reported diagnosis of a thyroid condition (yes/no, based on a single item from the household survey in Cycles 2 and 3 asked to respondents aged 12 years and older: 'Do you have a thyroid condition?'), (2) TSH level (low/normal/high) for respondents aged 3-79 years in Cycle 3 only and (3) blood test results indicating primary hypothyroidism (yes/no) for respondents aged 3-79 years in Cycle 3 only.

Determination of TSH level and primary hypothyroidism status was based on the non-environmental lab full sample file of the CHMS (new for Cycle 3) which contained four biomarkers of thyroid health: (1) TSH, (2) free T4, (3) antithyroid peroxidase and (4) antithyroglobulin. We used TSH and free T4 because they had the largest sample sizes and greatest clinical significance in terms of the most common thyroid disorders.

Blood samples of TSH and free T4 were collected at the mobile clinic by a phlebotomist using a standardised venipuncture method. The amount of blood drawn was dependent on the respondent's age. ${ }^{14}{ }^{15}$ Quantification of TSH in serum was determined using a third-generation assay analyser that has a chemiluminescent detection system. ${ }^{20}$ Serum levels of free T4 were analysed using a competitive chemiluminescent immunoassay. ${ }^{21}$ The reference intervals of TSH and free T4 were $0.55-4.78 \mathrm{mIU} / \mathrm{L}$ and $11.5-22.5 \mathrm{pmol} / \mathrm{L}$, respectively. Both TSH and free T4 samples were analysed at the Institut National de Santé Publique du Québec on the Siemens ADVIA Centaur XP analyser. $^{2021}$

Synthesised and secreted by the anterior pituitary gland, TSH stimulates the thyroid gland to produce T3 and T4, which play important roles in regulating metabolism. ${ }^{20}$ Approximately, $99.95 \%$ of T4 circulates in the blood reversibly bound to transport proteins, while the small percentage that is unbound, 
known as free T4, is metabolically active. ${ }^{21}$ Measuring blood levels of TSH is important in determining thyroid gland function. In primary hypothyroidism, a common thyroid disorder, TSH levels are significantly elevated. A reduced free T4 level also characterises primary hypothyroidism. ${ }^{20}$ Accordingly, we classified respondents as having primary hypothyroidism if they had elevated TSH levels $(>4.78 \mathrm{mIU} / \mathrm{L})$ and low free T4 levels $(<11.5 \mathrm{pmol} / \mathrm{L}) .^{2021}$

We adjusted for potential confounders (drawn from the household interview): sex, age, household education (highest attained education in the household: less than a Bachelor's degree vs Bachelor's degree or greater) and household income adequacy (low and middle income vs high income based on the total household income and household size). For analyses involving biomarkers of thyroid health (TSH and free T4), we excluded (1) pregnant women ${ }^{22}$ and (2) respondents who reported taking a thyroid medication in the past month at either the household or clinic interview, as thyroid medications could artificially bring an abnormal thyroid biomarker into the normal range.

Finally, we considered variables that permitted some discernment of source(s) of fluoride exposure. Our reasoning was as follows: if we observed an association between fluoride and thyroid functioning among the full subsample, observing whether that association was also present (or was stronger) among the subset of participants would provide us with a sense about the role of the source of fluoride exposure. For both Cycles 2 and 3, following an approach used elsewhere, ${ }^{23}$ we assigned each data collection site as 'fluoridated' or 'not fluoridated' using information obtained from a variety of sources (eg, municipal websites, water quality reports, news reports). The Office of the Chief Dental Officer, Public Health Agency of Canada, corroborated our classifications. Additionally, content from Cycle 2 allowed us to identify respondents who (1) identified tap water as their primary source of drinking water at home or away from home (vs bottled or other) and (2) indicated living in their current home for at least 3 years. New content related to water consumption for Cycle 3 allowed us to identify respondents who (1) reported using fluoride-containing products at home (eg, toothpaste, mouthwash) and (2) reported ever receiving fluoride treatments at the dentist (vs never).

\section{Data analysis}

First, we used logistic regression to regress self-reported diagnosis of a thyroid condition (yes/no) on urinary fluoride $(\mu \mathrm{mol} / \mathrm{L})$ for Cycles 2 and 3 and on fluoride concentration of tap water $(\mathrm{mg} / \mathrm{L})$ for Cycle 3, unadjusted and adjusted for covariates. Second, multinomial logistic regression was used to examine the relationship between fluoride exposure (from urine and tap water) and TSH (low/normal/high), unadjusted and adjusted for covariates. We intended to regress hypothyroidism status (yes/ no) on urinary fluoride and fluoride concentration of tap water but Statistics Canada sample size requirements precluded these analyses. Instead, our third analysis was simple mean comparison of urinary fluoride and fluoride concentration of tap water between respondents with and without hypothyroidism.

We again intended to rerun the same analyses among a subset of respondents for whom we could discern source(s) of fluoride exposure but again, we were unable to do so due to sample size requirements set by Statistics Canada. Instead, we performed mean comparisons to examine whether fluoride (from urine and tap water) differed between those with and without thyroid diagnosis, and those with low, normal, and high TSH level, among the constrained fluoride urine subsample.
Data access and analysis took place at the Prairie Regional Research Data Centre at the University of Calgary. As directed by Statistics Canada, all models incorporated survey weights to permit generalisation of findings back to the Canadian population and bootstrap weights to ensure the appropriate computation of variance estimates. Stata (V.14.1) software was used for all analyses. ${ }^{24}$ This study was exempt from formal ethics approval due to informed consent procedures in place at the time of data collection and integrity measures in place at the time of data analysis.

\section{RESULTS}

Descriptive statistics for Cycles 2 and 3 of the CHMS are presented in table 1. Missing data were less than 5\% for all analyses and thus considered inconsequential. ${ }^{25}$ One exception is income, which was reported by 71\% (Cycle 2) and 77\% (Cycle 3) of respondents. Statistics Canada imputed total household income so that values were available for all survey participants. ${ }^{14} 15$

Table $2 \mathrm{a}$ shows the results of logistic regression, with self-reported diagnosis of a thyroid condition (yes/no) regressed on urinary fluoride $(\mu \mathrm{mol} / \mathrm{L})$ for Cycles 2 and 3 and on fluoride concentration of tap water (mg/L) for Cycle 3, unadjusted and adjusted for covariates. None of the models show an association between the measures of fluoride exposure and self-reported diagnosis of a thyroid condition.

The results from multinomial logistic regression with TSH levels (low/normal/high) regressed on urinary fluoride $(\mu \mathrm{mol} / \mathrm{L})$ and on fluoride concentration of tap water $(\mathrm{mg} / \mathrm{L})$, unadjusted and adjusted for covariates are presented in table $2 \mathrm{~b}$. Neither urinary fluoride nor fluoride concentration of tap water was associated with an abnormal (low or high) TSH level compared with a normal TSH level.

Based on mean comparisons, urinary fluoride $(\mu \mathrm{mol} / \mathrm{L}) \mathrm{did}$ not differ between individuals classified as having primary hypothyroidism (mean $=31.78 \mu \mathrm{mol} / \mathrm{L}, \mathrm{SE}=10.28 \mu \mathrm{mol} / \mathrm{L}, 95 \%$ CI 11.63 to $51.93 \mu \mathrm{mol} / \mathrm{L})$ versus not $($ mean $=29.23 \mu \mathrm{mol} / \mathrm{L}$, $\mathrm{SE}=1.66 \mu \mathrm{mol} / \mathrm{L}, 95 \% \mathrm{CI} 25.97$ to $32.49 \mu \mathrm{mol} / \mathrm{L})$. Similarly, fluoride concentration or tap water $(\mathrm{mg} / \mathrm{L})$ did not differ between individuals classified as having primary hypothyroidism $($ mean $=0.36 \mathrm{mg} / \mathrm{L}, \mathrm{SE}=0.11 \mathrm{mg} / \mathrm{L}, 95 \% \mathrm{CI} 0.16$ to $0.57 \mathrm{mg} / \mathrm{L})$ versus not (mean $=0.22 \mathrm{mg} / \mathrm{L}, \mathrm{SE}=0.04 \mathrm{mg} / \mathrm{L}, 95 \% \mathrm{CI} 0.15$ to $0.30 \mathrm{mg} / \mathrm{L})$.

In table $3 \mathrm{a}$ and $\mathrm{b}$, we consider the subsample for which we could discern sources of fluoride exposure from drinking water and/or dental products. Neither the means of urinary fluoride $(\mu \mathrm{mol} / \mathrm{L})$ nor the means of fluoride concentration of tap water $(\mathrm{mg} / \mathrm{L})$ appear to differ between those who self-reported being diagnosed with a thyroid condition versus those who did not based on widely overlapping 95\% CIs, in this constrained subsample (table 3a). Similarly, individuals with low, normal and high TSH levels did not appear to differ in mean urinary fluoride $(\mu \mathrm{mol} / \mathrm{L})$ or fluoride concentration of tap water $(\mathrm{mg} / \mathrm{L})$, in this constrained subsample (table $3 \mathrm{~b}$ ). Those who were pregnant and/or taking a thyroid medication $(n=37)$ were not excluded from this analysis due to Statistics Canada sample size requirements, but these individuals comprised less than $5 \%$ of the total sample $(\mathrm{n}=\sim 820)$.

\section{DISCUSSION}

We did not detect any association between fluoride exposure (from urine and tap water) and (1) self-reported diagnosis of a thyroid condition or (2) abnormal (low or high) TSH levels, among a large, representative sample of the Canadian 


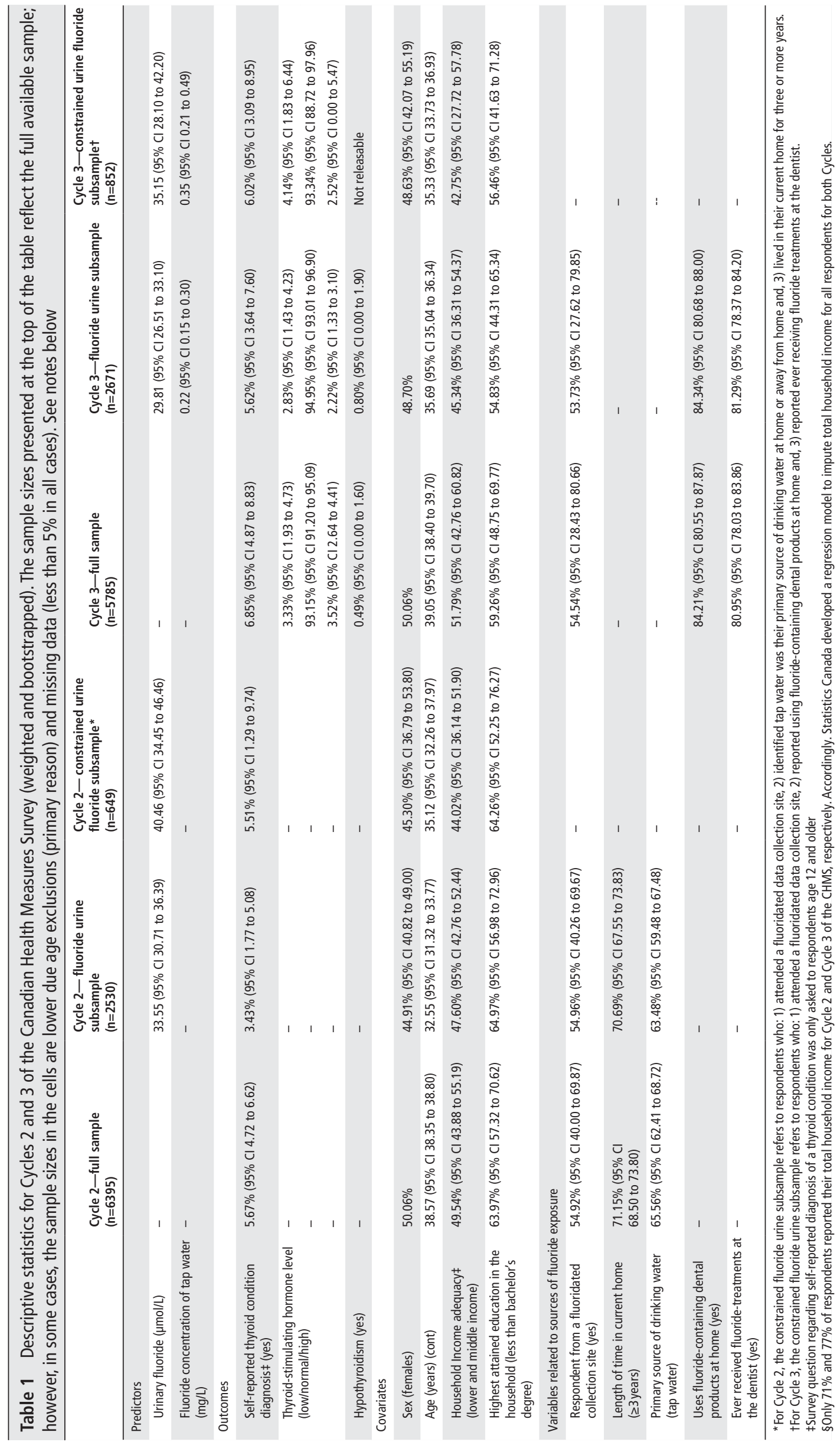


Table 2a Results from logistic regression where self-reported diagnosis of a thyroid condition was regressed on urinary fluoride (Cycles 2 and 3 ) and fluoride concentration of tap water (Cycle 3)

\begin{tabular}{|c|c|c|c|c|c|c|}
\hline \multirow[b]{2}{*}{ Predictor variable } & \multicolumn{2}{|l|}{ Cycle 2 of CHMS } & \multicolumn{4}{|l|}{ Cycle 3 of CHMS } \\
\hline & $\begin{array}{l}\text { Unadjustedt } \\
\text { estimates for fluoride } \\
\text { urine subsample } \\
(\mathrm{OR}, 95 \% \mathrm{Cl})\end{array}$ & $\begin{array}{l}\text { Adjusted } \neq \text { estimates } \\
\text { for fluoride urine } \\
\text { subsample } \\
(0 \mathrm{R}, 95 \% \mathrm{Cl}) \\
(\mathrm{n}=1466)\end{array}$ & $\begin{array}{l}\text { Unadjustedt } \\
\text { estimates for fluoride } \\
\text { urine subsample } \\
(\mathrm{OR}, 95 \% \mathrm{CI})\end{array}$ & $\begin{array}{l}\text { Adjusted } \ddagger \text { estimates } \\
\text { for fluoride urine } \\
\text { subsample } \\
(\mathrm{OR}, 95 \% \mathrm{Cl}) \\
(\mathrm{n}=1570)\end{array}$ & $\begin{array}{l}\text { Unadjustedt } \\
\text { estimates for fluoride } \\
\text { tap water subsample } \\
(\mathrm{OR}, 95 \% \mathrm{Cl})\end{array}$ & $\begin{array}{l}\text { Adjusted } \ddagger \text { estimates } \\
\text { for fluoride tap water } \\
\text { subsample } \\
(\mathrm{OR}, 95 \% \mathrm{CI}) \\
(\mathrm{n}=1564)\end{array}$ \\
\hline $\begin{array}{l}\text { Urinary fluoride } \\
\text { ( } \mu \mathrm{mol} / \mathrm{L}) \text { (cont) }\end{array}$ & $0.98(0.94$ to 1.03$)$ & $0.98(0.95$ to 1.02$)$ & $1.00(0.99$ to 1.02$)$ & $1.00(0.99$ to 1.01$)$ & - & - \\
\hline $\begin{array}{l}\text { Fluoride concentration } \\
\text { of tap water (mg/L) } \\
\text { (cont) }\end{array}$ & - & - & - & - & $0.92(0.22$ to 3.94$)$ & $0.98(0.28$ to 3.45$)$ \\
\hline Sex (ref: male) & $6.36^{*}$ (1.52 to 26.68$)$ & $6.31 *(1.29$ to 30.89$)$ & $4.09 *(1.27$ to 19.52$)$ & $4.20 *(0.90$ to 19.53$)$ & $4.00 *(1.02$ to 15.72$)$ & $4.13^{*}$ (0.94 to 18.21$)$ \\
\hline Age (years) (cont) & $1.04^{* *}(1.02$ to 1.07$)$ & $1.05^{* *}(1.02$ to 1.08$)$ & $1.05^{* *}(1.03$ to 1.08$)$ & $1.06^{* *}(1.03$ to 1.09$)$ & $1.05^{* *}(1.03$ to 1.08$)$ & $1.06^{* *}(1.03$ to 1.09$)$ \\
\hline $\begin{array}{l}\text { Household income } \\
\text { adequacy (ref: lower } \\
\text { and middle income) }\end{array}$ & $0.95(0.39$ to 2.35$)$ & 1.09 (0.29 to 4.07$)$ & $0.78(0.23$ to 2.61$)$ & $1.23(0.30$ to 5.03$)$ & 0.77 (0.22 to 2.64$)$ & $1.20(0.30$ to 4.83$)$ \\
\hline $\begin{array}{l}\text { Highest attained } \\
\text { education in the } \\
\text { household } \\
\text { (ref: less than } \\
\text { bachelor's degree) }\end{array}$ & 1.67 (0.84 to 3.28$)$ & $2.03(0.81$ to 5.10$)$ & $0.40^{* * *}(0.15$ to 1.10$)$ & $0.37^{* * *}(0.11$ to 1.22$)$ & $0.41 * * *(0.15$ to 1.11$)$ & $0.38(0.12$ to 1.26$)$ \\
\hline
\end{tabular}

tColumn contains bivariate associations between predictor variable and the outcome (self-reported diagnosis of a thyroid condition).

$\ddagger$ Column contains associations from single model containing all predictor variables (age, sex, household income adequacy and highest attained education in the household).

${ }^{*} \mathrm{p}<0.05,{ }^{* *} \mathrm{p}<0.01,{ }^{* * *} \mathrm{p}<0.1$

Note: these models were rerun using creatinine-adjusted urinary fluoride ( $\mu \mathrm{mol} / \mathrm{mmol}$ ) and no significant observations were detected (data not shown).

CHMS, Canadian Health Measures Survey; RRR, relative risk ratio; TSH, thyroid-stimulating hormone.

Table $2 \mathrm{~b}$ Results from multinomial logistic regression with TSH levels (low/normal/high) regressed on fluoride exposure from urine and tap water (Cycle 3 only). Pregnant women and those taking a thyroid medication were excluded from analyses

\begin{tabular}{|c|c|c|c|c|c|}
\hline \multirow[b]{2}{*}{ Predictor variable } & & \multicolumn{4}{|l|}{ Cycle 3 of CHMS } \\
\hline & & $\begin{array}{l}\text { Unadjustedt estimates } \\
\text { for fluoride urine } \\
\text { subsample } \\
(\mathrm{RRR}, 95 \% \mathrm{CI})\end{array}$ & $\begin{array}{l}\text { Adjusted } \ddagger \text { estimates for } \\
\text { fluoride urine subsample } \\
\text { (RRR, 95\% Cl) } \\
(n=2008)\end{array}$ & $\begin{array}{l}\text { Unadjustedt estimates } \\
\text { for fluoride tap water } \\
\text { subsample } \\
(\mathrm{RRR}, 95 \% \mathrm{CI})\end{array}$ & $\begin{array}{l}\text { Adjusted } ¥ \text { estimates } \\
\text { for fluoride tap water } \\
\text { subsample } \\
\text { (RRR, 95\% CI) } \\
(\mathrm{n}=2000)\end{array}$ \\
\hline \multirow{3}{*}{$\begin{array}{l}\text { Urinary fluoride } \\
\mu \mathrm{mol} / \mathrm{L})(\mathrm{co} ; n t)\end{array}$} & Low TSH & 1.01 (0.99 to 1.04$)$ & 1.01 (0.99 to 1.04$)$ & - & - \\
\hline & Normal TSH (ref) & - & - & & \\
\hline & High TSH & 0.99 (0.97 to 1.02$)$ & 0.99 (0.97 to 1.02$)$ & & \\
\hline \multirow{3}{*}{$\begin{array}{l}\text { Fluoride concentration of tap } \\
\text { water (mg/L) (cont) }\end{array}$} & Low TSH & - & - & 1.77 (0.20 to 15.86$)$ & 1.38 (0.08 to 24.49$)$ \\
\hline & Normal TSH (ref) & & & - & - \\
\hline & High TSH & & & $1.38(0.07$ to 27.00$)$ & $1.20(0.14$ to 10.08$)$ \\
\hline \multirow[t]{3}{*}{ Sex (ref: male) } & Low TSH & $1.04(0.28$ to 3.85$)$ & $1.03(0.26$ to 4.06$)$ & $1.03(0.28$ to 3.79$)$ & $0.98(0.24$ to 3.92$)$ \\
\hline & Normal TSH (ref) & - & - & - & - \\
\hline & High TSH & $0.97(0.15$ to 6.36$)$ & 0.89 (0.11 to 7.03$)$ & $0.96(0.14$ to 6.31$)$ & 0.91 (0.13 to 6.36$)$ \\
\hline \multirow[t]{3}{*}{ Age (years) (cont) } & Low TSH & 1.01 (0.99 to 1.04$)$ & 1.01 (0.98 to 1.05$)$ & 1.01 (0.99 to 1.04$)$ & $1.02(0.99$ to 1.05$)$ \\
\hline & Normal TSH (ref) & - & - & - & - \\
\hline & High TSH & $0.99(0.97$ to 1.00$)$ & $0.99(0.97$ to 1.01$)$ & $0.99(0.97$ to 1.00$)$ & 0.99 (0.96 to 1.01$)$ \\
\hline \multirow{3}{*}{$\begin{array}{l}\text { Household income adequacy } \\
\text { (ref: lower and middle income) }\end{array}$} & Low TSH & $1.87(0.71$ to 4.89$)$ & $1.97(0.65$ to 5.97$)$ & $1.89(0.72$ to 4.97$)$ & $1.98(0.64$ to 6.11$)$ \\
\hline & Normal TSH (ref) & - & - & - & - \\
\hline & High TSH & $1.66(0.30$ to 9.02$)$ & $1.94(0.26$ to 14.50$)$ & $1.67(0.30$ to 9.16$)$ & $1.88(0.26$ to 13.46$)$ \\
\hline \multirow{3}{*}{$\begin{array}{l}\text { Highest attained education in } \\
\text { the household } \\
\text { (ref: less than bachelor's } \\
\text { degree) }\end{array}$} & Low TSH & 0.84 (0.31 to 2.28$)$ & $0.70(0.22$ to 2.16$)$ & $0.85(0.31$ to 2.31$)$ & 0.71 (0.23 to 2.19$)$ \\
\hline & Normal TSH (ref) & - & - & - & - \\
\hline & High TSH & $0.99(0.10$ to 10.22$)$ & $0.80(0.07$ to 9.61$)$ & $1.00(0.10$ to 10.39$)$ & $0.82(0.07$ to 9.21$)$ \\
\hline
\end{tabular}

†Column contains bivariate associations between predictor variable and the outcome (TSH level (low/normal/high)).

$¥$ Column contains associations from single model containing all predictor variables (age, sex, household income adequacy and highest attained education in the household).

${ }^{*} \mathrm{p}<0.05,{ }^{* *} \mathrm{p}<0.01,{ }^{* * *} \mathrm{p}<0.1$.

Note: these models were rerun using creatinine-adjusted urinary fluoride ( $\mu \mathrm{mol} / \mathrm{mmol}$ ) and no significant observations were detected (data not shown).

CHMS, Canadian Health Measures Survey; RRR, relative risk ratio; TSH, thyroid-stimulating hormone. 
Table 3a Mean comparisons of urinary fluoride (Cycles 2 and 3) and fluoride concentration of tap water (Cycle 3) between those with and without a self-reported diagnosis of a thyroid condition among the constrained fluoride urine subsample (weighted and bootstrapped)

\begin{tabular}{|c|c|c|c|}
\hline & \multirow{2}{*}{$\begin{array}{l}\text { Cycle } 2 \text { of CHMS } \\
\text { Mean urinary fluoride ( } \mu \mathrm{mol} / \mathrm{L}) \\
\text { for the constrained fluoride } \\
\text { subsample* }(\mathrm{n}=\sim 390)\end{array}$} & \multicolumn{2}{|l|}{ Cycle 3 of CHMS } \\
\hline & & $\begin{array}{l}\text { Mean urinary fluoride }(\mu \mathrm{mol} / \mathrm{L}) \\
\text { for the constrained fluoride } \\
\text { subsamplet }(n=\sim 590)\end{array}$ & $\begin{array}{l}\text { Mean fluoride concentration of tap } \\
\text { water (mg/L) for the constrained } \\
\text { fluoride subsamplet ( } n=\sim 590)\end{array}$ \\
\hline $\begin{array}{l}\text { Has not been diagnosed with a thyroid } \\
\text { condition }\end{array}$ & 41.61 (34.50 to 48.72$)$ & $34.18(26.30$ to 42.06$)$ & 0.35 (0.20 to 0.49$)$ \\
\hline $\begin{array}{l}\text { Has been diagnosed with a thyroid } \\
\text { condition }\end{array}$ & $38.60(30.12$ to 47.00$)$ & 39.58 (29.27 to 49.89$)$ & 0.33 (0.16 to 0.51$)$ \\
\hline
\end{tabular}

*For Cycle 2, the constrained fluoride urine subsample refers to respondents who: 1) attended a fluoridated data collection site, 2) identified tap water was their primary source of drinking water at home or away from home and, 3) lived in their current home for three or more years.

tFor Cycle 3, the constrained fluoride urine subsample refers to respondents who: 1) attended a fluoridated data collection site, 2) reported using fluoride-containing dental products at home and, 3) reported ever receiving fluoride treatments at the dentist.

CHMS, Canadian Health Measures Survey; TSH, thyroid-stimulating hormone.

Table 3b Mean comparisons of urinary fluoride and fluoride concentration of tap water (Cycle 3) between those with and with low, normal and high TSH levels among the constrained fluoride urine subsample (weighted and bootstrapped)

\begin{tabular}{lll}
\hline & Cycle 3 of CHMS & \\
\cline { 2 - 3 } & $\begin{array}{l}\text { Mean urinary fluoride }(\mu \mathrm{mol} / \mathrm{L}) \text { for the constrained } \\
\text { fluoride subsample* }(\mathbf{n}=\sim 820)\end{array}$ & $\begin{array}{l}\text { Mean fluoride concentration of tap water }(\mathbf{m g} / \mathbf{L}) \text { for } \\
\text { the constrained fluoride subsample* }(\mathbf{n}=\sim 820)\end{array}$ \\
\hline Low TSH $(<0.55 \mathrm{mlU} / \mathrm{L})$ & $40.01(24.35$ to 55.67$)$ & $0.34(0.16$ to 0.51$)$ \\
Normal TSH $(0.55$ to $4.78 \mathrm{mlU} / \mathrm{L})$ & $33.92(26.79$ to 41.05$)$ & $0.35(0.21$ to 0.49$)$ \\
High TSH $(>4.78 \mathrm{mlU} / \mathrm{L})$ & $30.76(17.89$ to 43.63$)$ & $0.38(0.19$ to 0.57$)$ \\
\hline
\end{tabular}

*For Cycle 3, the constrained fluoride urine subsample refers to respondents who: 1) attended a fluoridated data collection site, 2) reported using fluoride-containing dental products at home and, 3) reported ever receiving fluoride treatments at the dentist.

CHMS, Canadian Health Measures Survey; TSH, thyroid-stimulating hormone.

population. The absence of association applied to both the full fluoride urine subsample and the constrained fluoride urine subsample for which we could discern some source(s) of fluoride exposure from drinking water and/or use of dental products. Taken together, these findings suggest that, at the population level in Canada, fluoride exposure does not contribute to impaired thyroid functioning during a time where multiple sources of fluoride exposure, including CWF, exist.

Our findings appear to contradict the conclusions of the only other population-level study conducted on this topic to-date, by Peckham et al (2015). ${ }^{13}$ These opposing findings could reflect: (1) differences in country-specific recommendations for optimal concentration of artificial fluoride added to drinking water (1 ppm in England vs 0.7 ppm in Canada), ${ }^{11} 13$ (2) differences in the methods used (ie, individual-level measures used here vs ecological measures used by Peckham et al (2015)) $)^{13}$ and/or (3) differences in factors related to hypothyroidism within the underlying populations of both studies. One example is prescription medication use. Although beyond the scope of this discussion, it is important to acknowledge that several prescription medications can interfere with thyroid function tests or induce thyroid diseases, ${ }^{26}$ and the use of these medications may differ between countries. Another potentially important factor is iodine intake. Data from the Iodine Global Network indicates that the population iodine status for Canada is 'adequate', whereas the population iodine status for the UK is 'mild deficiency'. ${ }^{27}$ This could reflect that Canada adopted mandatory iodisation of all foodgrade salt in 1949, whereas the UK has never had recommended or mandatory iodised salt programme. ${ }^{28} 29$ A recent study estimated the weighted availability of iodised salt in UKs' supermarkets to be $21.5 \%$, which the authors conclude is unlikely to confer adequate protection against iodine deficiency. ${ }^{29}$

Some limitations of our study include: (1) possible reporting bias related to self-reported diagnosis of a thyroid condition; because one's level of fluoride exposure is unlikely to influence their reporting of thyroid outcomes, the resulting non-differential misclassification could have diluted the reported associations, (2) information on some potentially important covariates such as family history of thyroid disease were not available in the CHMS and (3) spot urine samples used to measure urinary fluoride are susceptible to fluctuations. ${ }^{30}$ Additionally, we are not able to discern causality due to the cross-sectional nature of the survey data. Major strengths of this study include: (1) the large, representative nature of the sample, (2) extensive data validation and quality control measures and (3) individual-level estimates of both fluoride exposure and biomarkers of thyroid health.

In conclusion, findings suggest that current levels of fluoride exposure do not increase susceptibility to impaired thyroid functioning at the population-level in Canada. These findings may be broadly relevant to other countries with similar populations and CWF schemes and provide an important complement to existing clinical and/or basic science studies on fluoride exposure and thyroid outcomes. Decision-makers can consider the results of the present research in addition to the larger body of scientific literature on risks, benefits, economic evaluations, etc., when determining if fluoride concentrations in their municipality's water supply need to be altered. These results can also contribute to informed public debate surrounding CWF.

Future research should utilise this rich, high-quality data source to explore relationships between fluoride exposure and other potential harms. We also recommend that future cycles of the CHMS collect data on fluoride biomarkers that capture recent fluoride exposure (eg, hair samples or fingernail clippings), rather than, or in addition to, those that measure contemporary fluoride exposure (urine), so that exposure may be more accurately defined. ${ }^{19}$ 


\section{What is already known on this subject}

- Concerns exist that community water fluoridation could compromise thyroid functioning. A recent population-level study from England appears to add credibility to this concern as a positive association between the fluoride concentration in drinking water and hypothyroidism prevalence was found. It is important to investigate whether this observed association is consistent among different populations and settings.

\section{What this study adds}

- Using newly released, nationally representative Canadian survey data, we did not detect an association between individual-level fluoride exposure (from urine and tap water) and impaired thyroid functioning, as measured by self-reported diagnosis of a thyroid condition or abnormal thyroid-stimulating hormone level. Future research should utilise this rich data source to explore relationships between fluoride exposure and other potential harms.

Acknowledgements We thank Dr Diane Lorenzetti, Department of Community Health Sciences at the University of Calgary, for providing research support, Dr Charlie Victorino and Dr Rebecca Williams, Research Analysts at the Prairie Regional Research Data Centre, and Jeanne Williams and Dina Lavorato, for providing methodological support and assistance. We also thank Dr Martin Chartier and Dr Annie Bronsard, Public Health Agency of Canada, for their input and assistance with verifying fluoridation status information from across Canada.

Contributors All the authors provided substantial input to the study design, the acquisition, analysis and interpretation of the data, writing the manuscript and revising it critically and provided final approval of the version of the manuscript to be published. All the authors agreed to be accountable for all aspects of the work in ensuring that questions related to the accuracy or integrity of any part of the work are appropriately investigated and resolved.

Funding This work was supported by an Applied Public Health Chair award funded by Canadian Institute of Health Research (CIHR) (Institute of Population and Public Health and Institute of Musculoskeletal Health and Arthritis), the Public Health Agency of Canada, and Alberta Innovates-Health Solutions (LM).

\section{Competing interests None declared.}

Provenance and peer review Not commissioned; externally peer reviewed.

Open Access This is an Open Access article distributed in accordance with the Creative Commons Attribution Non Commercial (CC BY-NC 4.0) license, which permits others to distribute, remix, adapt, build upon this work non-commercially, and license their derivative works on different terms, provided the original work is properly cited and the use is non-commercial. See: http://creativecommons.org/ licenses/by-nc/4.0/

(c) Article author(s) (or their employer(s) unless otherwise stated in the text of the article) 2017. All rights reserved. No commercial use is permitted unless otherwise expressly granted.

\section{REFERENCES}

1 Hall JE. Guyton and hall textbook of medical physiology: Elsevier Health Sciences, 2015
2 Manji N, Carr-Smith JD, Boelaert K, et al. Influences of age, gender, smoking, and family history on autoimmune thyroid disease phenotype. J Clin Endocrinol Metab 2006;91:4873-80.

3 Elfström P, Montgomery SM, Kämpe 0, et al. Risk of thyroid disease in individuals with celiac disease. J Clin Endocrinol Metab 2008;93:3915-21.

4 National Research Council. Fluoride in drinking water: a scientific review of EPA's standards. Washington DC, USA: The National Academies Press, 2006.

5 Michael M, Barot VV, Chinoy NJ. Investigations of soft tissue functions in fluorotic individuals of North Gujarat. Fluoride 1996;29:63-71.

6 Susheela AK, Bhatnagar M, Vig K. Excess fluoride ingestion and thyroid hormone derangements in children living in Delhi. India Fluoride 2005;38:98-108.

7 Singh $N$, Verma KG, Verma P, et al. A comparative study of fluoride ingestion levels, serum thyroid hormone \& TSH level derangements, dental fluorosis status among school children from endemic and non-endemic fluorosis areas. Springerplus 2014;3:7-5.

8 Lin FF, Aihaiti HX, Zhao J, et al. The relationship of a low iodine and high-fluoride environment to subclinical cretinism in Xinjiang. IDD Newsletter 1991;7:24-5.

9 Hosur MB, Puranik RS, Vanaki S, et al. Study of thyroid hormones free triiodothyronine (FT3), free thyroxine (FT4) and thyroid stimulating hormone (TSH) in subjects with dental fluorosis. Eur J Dent 2012;6:184-90.

10 Sutton M, Kiersey R, Farragher L, et al. Health effects of water fluoridation. Dublin, Ireland: Health Research Board, 2015

11 Health Canada. Findings and recommendations of the fluoride expert panel, 2008.

12 Podgorny PC, McLaren L. Public perceptions and scientific evidence for perceived harms/risks of community water fluoridation: an examination of online comments pertaining to fluoridation cessation in Calgary in 2011. Can J Public Health 2015;106:e413-e25.

13 Peckham S, Lowery D, Spencer S. Are fluoride levels in drinking water associated with hypothyroidism prevalence in England? A large observational study of GP practice data and fluoride levels in drinking water. J Epidemiol Community Health 2015;69:619-24.

14 Statistics Canada. Canadian Health Measures Survey (CHMS). Data user guide: Cycle 2, 2013.

15 Statistics Canada. Canadian Health Measures Survey (CHMS). Data user guide: Cycle 3, 2015

16 Institut National de Santé Publique du Québec (INSPQ): Centre de toxicology. Analytic Method for the Determination of Fluoride in Urine (M-186)-Condensed Version for CHMS. 2009

17 Health Canada. Second Report on Human Biomonitoring of Environmental Chemicals in Canada: Results of the Canadian Health Measures Survey Cycle 2 (2009-2011). Ottawa, ON: Health Canada. 2013

18 Marthaler TM, Schulte AG. Monitoring salt fluoridation programs through urinary excretion studies. Schweiz Monatsschr Zahnmed 2005;115:679-84.

19 Mehta A. Biomarkers of fluoride exposure in human body. Indian J Dent 2013:4:207-10.

20 Health Canada. Analytic procedure manual: Third Generation UItra THYROID STIMULATING HORMONE (TSH3-UL) on ADVIA Centaur XP: Division. CRLNR, 2012.

21 Health Canada. Analytic procedure manual: free thyroxine (FT4) on ADVIA Centaur XP: CHMS Reference Laboratory: Nutrition Research Division, 2012.

22 American Thyroid Association website. Thyroid disease and pregnancy, 2016. http:// www.thyroid.org/thyroid-disease-pregnancy/ (accessed Jul 2016).

23 McLaren L. Fluoridation exposure status based on location of data collection in the Canadian health measures survey: is it valid? J Can Dent Assoc 2016;82:1-7.

24 StataCorp. Stata Statistical Software: release 14.1. College Station TX, USA: StataCorpLP. 2015.

25 Schafer JL. Multiple imputation: a primer. Stat Methods Med Res 1999;8:3-15.

26 Dong BJ. How medications affect thyroid function. West J Med 2000;172:102-6.

27 lodine Global Network. http://www.ign.org/ (accessed Jun 2017).

28 Canadian Public Health Association. Food fortification with vitamins and minerals. http://www.cpha.ca/en/programs/history/achievements/09-shf/fortification.aspx (accessed Jun 2017).

29 Bath SC, Button S, Rayman MP. Availability of iodised table salt in the UK: is it likely to influence population iodine intake? Public Health Nutr 2014;17:450-4.

30 Federal-Provincial-Territorial Committee on Drinking Water. Guidelines for Canadian drinking water quality: guideline technical document - fluoride. Ottawa, ON Health Canada, 2010. 